Nota de investigación

\title{
Calidad poscosecha de frutos de chayote almacenados a baja temperatura
}

\author{
Laura Angélica Montecinos-Pedro ${ }^{1}$ \\ Ma. de Lourdes Arévalo-Galarza ${ }^{1 \S}$ \\ Cecilia García-Osorio ${ }^{1}$ \\ Jorge Cadena-Iñiguez ${ }^{2}$ \\ Martha Elva Ramírez-Guzmán ${ }^{3}$
}

${ }^{1}$ Campus Montecillo-Colegio de Postgraduados. Carretera México-Texcoco km 36.5, Montecillo, Texcoco, Estado de México. CP. 56230. (montecinos.laura@colpos.mx; gcecilia@colpos.mx). ${ }^{2}$ Campus San Luis Potosí-Colegio de Postgraduados. Salinas de Hidalgo, San Luis Potosí, México. CP. 78622. (jocadena@colpos.mx). ${ }^{3}$ Posgrado en Estadística-Colegio de Postgraduados. Carretera México-Texcoco km 36.5, Montecillo, Texcoco, Estado de México. CP. 56230. (martarg@ colpos.mx).

${ }^{\S}$ Autora para correspondencia: larevalo@colpos.mx.

\section{Resumen}

El chayote nigrum spinosum es uno de los principales genotipos que se comercializan en México, Estados Unidos de América y Canadá, siendo las comunidades latina y asiática sus mayores consumidores. Generalmente los trabajos reportados en esta especie se centran en el genotipo virens levis, pero existe muy poca información del comportamiento poscosecha del genotipo $n$. spinosum bajo almacenamiento refrigerado. Para ello se cosecharon frutos en madurez hortícola y se almacenaron a temperatura ambiente $\left(20 \pm 2{ }^{\circ} \mathrm{C}\right)$ y a baja temperatura $\left(10 \pm 1{ }^{\circ} \mathrm{C}, 85 \% \mathrm{HR}\right)$ durante tres periodos de tiempo (3, 6 y 9 semanas) con y sin la aplicación de 1-metilciclopropeno $\left(0,500\right.$ y $\left.1000 \mathrm{~nL} \mathrm{~L}^{-1}\right)$ para reducir el viviparismo. Las variables evaluadas fueron: porcentaje de humedad, acidez titulable, SST ( ${ }^{\circ}$ Brix), contenido de clorofila $a$ y $b$ y total, contenido de azúcares totales (sacarosa, fructosa y glucosa), pérdida de peso y porcentaje de viviparismo. Los resultados mostraron un contenido promedio de humedad de 94\%, con bajo contenido de SST (4.5-5.2\%) que permanece sin cambios durante el almacenamiento, un contenido de fructosa y glucosa de $1.07 \%$ y $0.89 \%$ respectivamente, sin la presencia de sacarosa. Los frutos mantuvieron sus características de apariencia con el almacenamiento refrigerado por 3 semanas, pero a 6 y 9 semanas, fue evidente la deshidratación de espinas, aunque ambas dosis de 1-MCP (500 y $\left.1000 \mathrm{~nL} \mathrm{~L}^{-1}\right)$ redujeron significativamente el viviparismo, incrementaron la susceptibilidad a la incidencia de hongos principalmente Fusarium sp.

Palabras clave: clorofila, deshidratación, espinas, viviparismo.

Recibido: julio de 2019

Aceptado: agosto de 2019 
El chayote (Sechium edule Jacq. Sw.) cuyo nombre en náhuatl chayotl significa 'calabaza espinosa', es originario de Mesoamérica y presenta una amplia variación en la forma y color de frutos (SINAREFI, 2015). Este fruto tiene propiedades como diurético y antiinflamatorio, evita calcificaciones renales y arteriosclerosis, lo que reduce los riesgos cardiovasculares (Jensen y Lai, 1986). De la amplia riqueza biológica del chayote, en México se comercializan principalmente dos genotipos: virens levis (verde liso) y nigrum spinosum (negro espinoso). Ambos genotipos se exportan a Estados Unidos de América y Canadá debido a la creciente población latina y asiática.

La vida de anaquel de los frutos se ve limitada por la pérdida de color, deshidratación y presencia de viviparismo (germinación de la semilla al interior del fruto), que es uno de los factores que limita la vida de anaquel y es un motivo de rechazo durante la comercialización en ambos genotipos de fruto. El viviparismo es un fenómeno asociado con la biosíntesis de etileno, para que este regulador del crecimiento actúe tiene que ser reconocido por el receptor, conduciendo la activación transcripcional de los genes que desencadenan diversas respuestas fisiológicas como la germinación (Sisler y Serek, 1997; Blankenship, 2001).

Estudios recientes muestran que la aplicación de 1-MCP (1-metilciclopropeno) previene el reconocimiento del receptor al etileno, pues tiene mayor afinidad, y no puede activar los mecanismos que llevan a los procesos de germinación por lo que cierta efectividad en retrasar el viviparismo. En el caso del chayote virens levis al aplicar $300 \mathrm{~nL}$ de 1-MCP a frutos almacenados durante 28 días a $10{ }^{\circ} \mathrm{C}$, más $6 \mathrm{~d}$ a temperatura ambiente, se observó solo $5 \%$ del total de frutos mostró viviparismo comparado con $50 \%$ de los frutos testigo (Cadena-Iñiguez et al., 2006). Sin embargo, se desconoce si el 1-MCP puede tener la misma efectividad en los frutos del genotipo nigrum spinosum, ya que no existe información al respecto.

Por lo anterior el objetivo del presente estudio fue evaluar y generar información de los efectos del uso de 1-MCP sobre la vida de anaquel y calidad postcosecha bajo almacenamiento refrigerado del chayote nigrum spinosum.

\section{Material vegetal}

Se cosecharon 120 frutos sanos, sin heridas, en madurez hortícola y sin presencia de viviparismo (Figura 1).

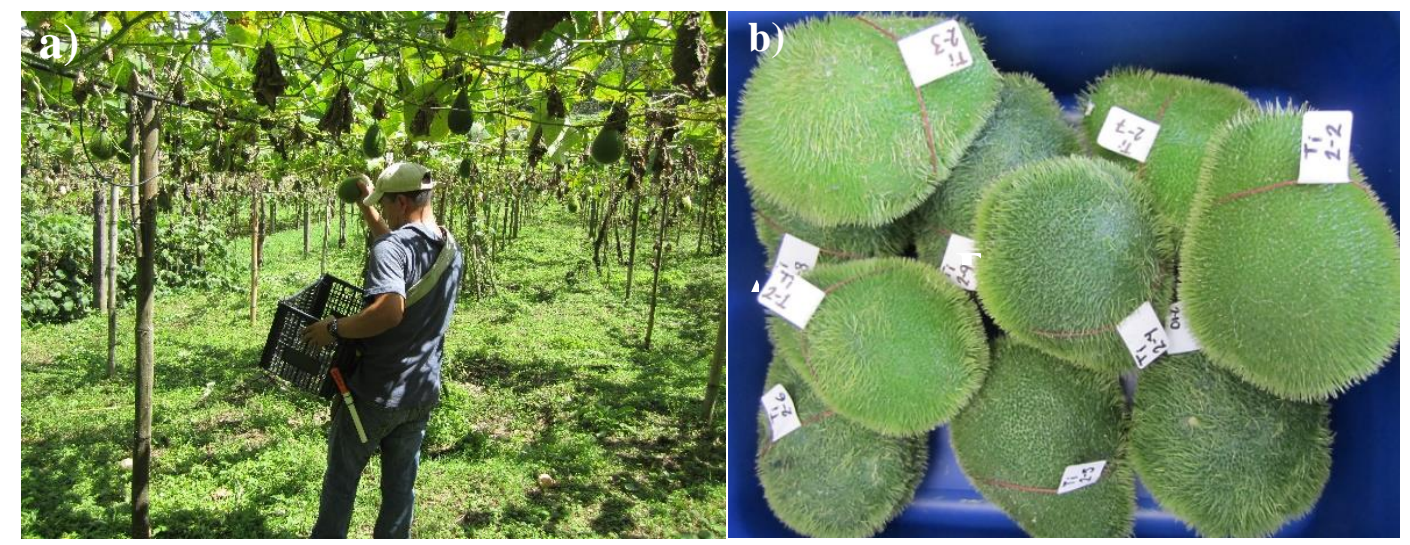

Figura 1. a) cosecha y b) apariencia de frutos chayote nigrum spinosum provenientes del Banco de Germoplasma de Sechium edule (BANGESe) en Huatusco Veracruz. 
La cosecha se realizó en noviembre de 2016, en el Banco Nacional de Germoplasma de Sechium edule (BANGESe), ubicado en el Centro Regional Universitario Oriente (CRUO), que pertenece a la Universidad Autónoma Chapingo (UACH) en el municipio de Huatusco, Veracruz, México (19 ${ }^{\circ}$ 08 ' 48' latitud norte y $97^{\circ} 57^{\prime} 00^{\prime \prime}$ latitud oeste).

La vegetación del lugar es de bosque mesófilo de montaña (1340 m de altitud) y temperatura media anual de $19{ }^{\circ} \mathrm{C}$ y $85 \% \mathrm{HR}$, con $2250 \mathrm{~mm}$ de precipitación media anual (Cadena-Iñiguez et al., 2006). Los frutos fueron transportados en cajas de plástico al laboratorio de Poscosecha del Colegio de Postgraduados, Montecillo, México.

Los chayotes se sumergieron en una solución de hipoclorito de sodio $(0.1 \%)$ durante 2 min, después se dejaron secar a temperatura ambiente durante $3 \mathrm{~h}$. Los frutos se dividieron en 12 lotes de 10 frutos cada uno, considerando cada lote un tratamiento (4 tiempos de almacenamiento: 0 (temperatura ambiente) 3, 6, 9 semanas (refrigeración) y 3 dosis de $1-\mathrm{MCP}\left(0,500\right.$ y $\left.100 \mathrm{~nL} \mathrm{~L}^{-1}\right)$. La aplicación de 1-MCP (SmartFresh ${ }^{\circledR} ; 14 \%$, Rohm and Haas Co.) fue por exposición durante $6 \mathrm{~h}$ a $20{ }^{\circ} \mathrm{C}$, colocando los frutos en un empaque herméticamente cerrado donde se colocó un vial con la concentración determinada de 1-MCP. Posteriormente los frutos se mantuvieron a temperatura ambiente $\left(20 \pm 2{ }^{\circ} \mathrm{C}\right)$ y bajo refrigeración a $10 \pm 1{ }^{\circ} \mathrm{C}$ por diferentes periodos de tiempo de acuerdo al tratamiento.

Las variables pérdida de peso y viviparismo se midieron cada dos días sin destruir los frutos, tanto a temperatura ambiente como a la salida de la cámara frigorífica. Mientras que los análisis químicos se realizaron a la salida de la cámara frigorífica y al día 11.

\section{Variables evaluadas}

\section{Porcentaje de humedad}

Se tomó una rodaja de $1 \mathrm{~cm}$ de espesor del centro del chayote, (sin epidermis ni semilla) y se colocó dentro de un horno mecánico de convección (Lab-Line Imperial V, Alpha Multiservises, Inc. USA) a $50{ }^{\circ} \mathrm{C}$ durante 8 días obteniendo un peso constante. La humedad se calculó con la ecuación:

Porcentaje de humedad $(\%)=\frac{\text { peso humedo-peso seco }}{\text { peso humedo }} * 100$

\section{Acidez titulable}

Se determinó por el método volumétrico de la AOAC (1990) en $2 \mathrm{~g}$ de pulpa licuada en $10 \mathrm{~mL}$ de agua destilada. Se tomó una alícuota de $5 \mathrm{~mL}$ y se le adicionaron 3 gotas de indicador de fenolftaleína. Posteriormente se tituló con $\mathrm{NaOH}$ hasta el vire. El resultado se expresó como porcentaje de ácido cítrico.

\section{Determinación de SST ( ${ }^{\circ}$ Brix)}

Fue determinado con un refractómetro digital (PAL-1, Atago ${ }^{\mathrm{TM}}$, Japón) en 5 frutos en cada periodo de evaluación, para ello se hicieron cortes en dos áreas de la región ecuatorial de cada fruto a una profundidad de $\pm 2.5 \mathrm{~cm}$ (mesocarpo) y subsecuentemente se exprimió con una tela. 


\section{Contenido de clorofila}

Se colocaron $2 \mathrm{~g}$ de la pulpa en un vial con tapa, se le adicionaron $10 \mathrm{~mL}$ de acetona (80 \%) y se almacenaron en condiciones de oscuridad durante $24 \mathrm{~h}$ y a temperatura ambiente. Después, el extracto se midió en tres longitudes de onda: 470, 646 y $663 \mathrm{~nm}$ en un espectrofotómetro UV (Thermo Scientific ${ }^{\mathrm{TM}}$, modelo Genesys ${ }^{\mathrm{TM}}$ 10UV). Para obtener las concentraciones de clorofilas $\left(\mathrm{mg} \mathrm{g}^{-1}\right)$ se aplicó las ecuaciones para el solvente de acetona al $80 \%$ (v/v), según Lichtenthaler (1987):

Clorofila a: $\mathrm{C}_{\mathrm{a}}=\left(12.25 * \mathrm{~A}_{663}-2.79 * \mathrm{~A}_{646}\right)$

Clorofila b: $\mathrm{C}_{\mathrm{b}}=\left(21.5 * \mathrm{~A}_{646}-5.1 * \mathrm{~A}_{663}\right)$

Clorofila total: $\mathrm{C}_{\mathrm{a}+\mathrm{b}}=\left(7.15 * \mathrm{~A}_{663}-18.71 * \mathrm{~A}_{646}\right)$

Total de carotenoides: $\mathrm{C}_{\mathrm{x}+\mathrm{c}}=\frac{1000 * \mathrm{~A}_{470}-1.82 \mathrm{C}_{a}-85.02 \mathrm{C}_{b}}{198}$

\section{Contenido de azúcares totales por HPLC}

Para la muestra madre se colocó en un matraz $5 \mathrm{~g}$ de pulpa de chayote finamente picada y se le agregó $60 \mathrm{~mL}$ de etanol al 80\% tapándolo con un trozo de papel aluminio. Se dejó reposar durante $24 \mathrm{~h}$ a temperatura ambiente y posteriormente se concentró. La solución se filtró con un acrodisco (Titan, $0.45 \mu \mathrm{m}$ ) y se colocó en un vial y se analizó por HPLC (High-Performance Liquid Chromatography) (series 200, Perkin Elmer ${ }^{\mathrm{TM}}$ ) con automuestreador y detector índice de refracción (IR). Se utilizó una columna Pinnacle II amino de 5 mm 150 x 4.6 mm (Restek ${ }^{\mathrm{TM}}$ ), la fase móvil fue una solución de acetonitrilo/agua (80:20) (v/v) con un tiempo de corrida de 14 min.

Para las curvas de calibración se pesaron por separado $0.05 \mathrm{~g}$ de fructosa, glucosa y sacarosa al 99.5\% (Sigma-Aldrich, USA) en $10 \mathrm{~mL}$ de metanol: agua (1:9) (v/v), se realizaron las diluciones correspondientes $\left(0.15\right.$ a $\left.5 \mathrm{mg} \mathrm{mL}^{-1}\right)$. Las condiciones del cromatógrafo fueron $35^{\circ} \mathrm{C}$, flujo de 1 $\mathrm{mL} \mathrm{min}^{-1}$, con un volumen de inyección de $10 \mu \mathrm{L}$.

\section{Pérdida de peso}

Se registró cada dos días el peso de cada chayote que permaneció a temperatura ambiente hasta presentar viviparismo, calculándolo con la siguiente ecuación:

$(\%)$ pérdida de peso $=\frac{\text { peso inicial-peso final }}{\text { peso inicial }} * 100$

\section{Viviparismo}

Cada dos días se registró la presencia de viviparismo de acuerdo con nivel de abertura de la parte basal del fruto (Figura 2) siendo: nivel $0=$ ausencia de semilla (valor nominal 0), nivel 1: apertura basal del fruto con la semilla visible, (valor nominal 2), nivel 2: semilla expuesta del fruto, (valor nominal 4), con la siguiente fórmula :\% viviparismo $=((\mathrm{n} \times \mathrm{v}) / \mathrm{tf}) \times 100$; donde $\mathrm{n}=$ número de frutos, $\mathrm{v}=$ nivel de viviparismo; $\mathrm{tf}=$ total de frutos en evaluación (Figura 2). 


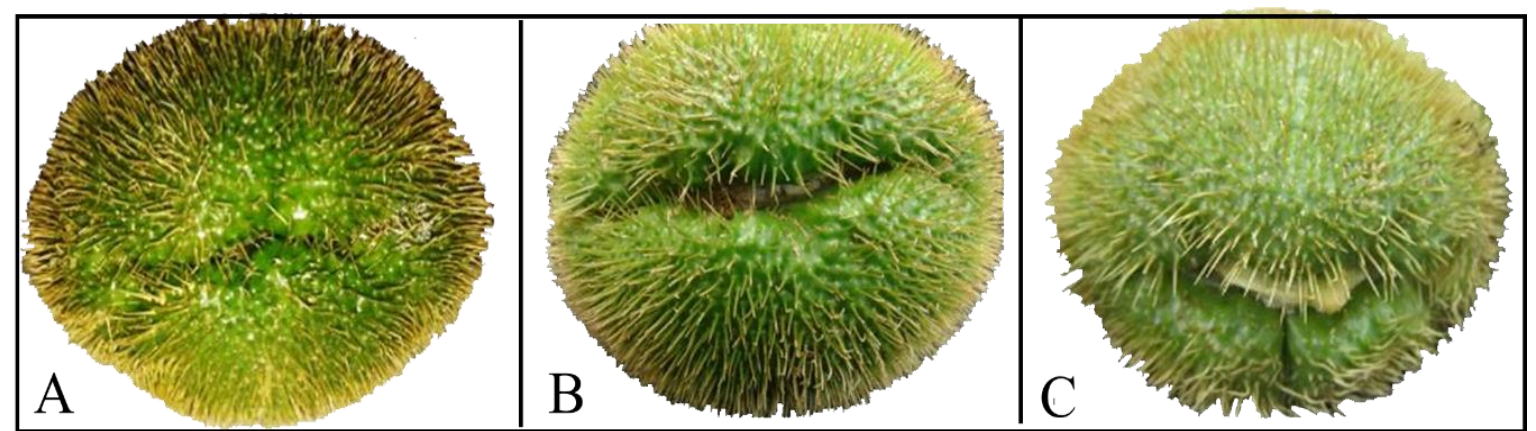

Figura 2. Clasificación de viviparismo en chayote nigrum spinosum. A: nivel 0= 0; B: nivel 1=2; C: nivel $2=4$.

\section{Diseño experimental}

Para las variables de calidad (\%SST, contenido de clorofila, acidez titulable y porcentaje de humedad), se usó un modelo con un diseño experimental factorial 4 x 3 x 2. Los niveles de los factores fueron: semana $(0,3,6,9)$, dosis de $1-\operatorname{MCP}(0,500,1000)$ y días de evaluación (1 y 11$)$.

$Y_{i j k}=\mu+S_{i}+M_{j}+D_{k}+S M_{i j}+S D_{i k}+M_{j k}+S M D_{i j k}+\varepsilon_{i j k}$

Donde: $\mathrm{Y}_{\mathrm{ijk}}=$ variable de respuesta proveniente de la i-ésima semana en la j-ésima dosis de 1- MCP en la k-ésimo día; $\mu=$ media general; $S_{\mathrm{i}}=$ efecto de la i-ésima semana ( $\left.\mathrm{i}=0,3,6,9\right) ; \mathrm{M}_{\mathrm{j}}=$ efecto del j-esimo dosis de 1- MCP $(\mathrm{j}=0,500,1000) ; \mathrm{D}_{\mathrm{k}}=$ efecto de la i-ésima día $(\mathrm{k}=1,11) ; \mathrm{SM}_{\mathrm{ijk}}=$ interacción semana*dosis de 1- $\mathrm{MCP} ; \mathrm{SMD}_{\mathrm{ijk}}=$ interacción semana $*$ dosis de $1-\mathrm{MCP} * \mathrm{día} ; \varepsilon_{\mathrm{ijk}}=$ error experimental; donde: $\mathrm{N}\left(0, \sigma^{2}\right)$.

En el caso de las variables: contenido de azúcares totales, fructosa, glucosa por HPLC se realizó un diseño experimental factorial 4 x 3 . Los factores fueron: semanas de almacenamiento y dosis de 1-MCP. Los niveles de los factores fueron: semana $(0,3,6,9)$, dosis de 1-MCP (0, 500, 1000$)$. Para la relación entre las variables de pérdida de peso (\%) y viviparismo (\%), se realizó un análisis de correlación para obtener el coeficiente de correlación de Pearson $(\alpha=0.05)$. Todos los datos se analizaron con el software estadístico InfoStat (Di-Rienzo et al., 2016).

\section{Discusión}

Una excelente calidad de los frutos de chayote espinoso se aprecia por el color verde oscuro del exocarpio, tamaño uniforme, espinas firmes y ausencia de viviparismo. Estos frutos se distinguen de los virens levis por ser jugosos y destacan de compuesto fenólicos (525 mg $100 \mathrm{~g}^{-1}$ ) y cucurbitacinas (137 mg $100 \mathrm{~g} \mathrm{~g}^{-1}$ ). De acuerdo con el Cuadro 1, los frutos de nigrum spinosum tienen en promedio de materia seca entre 5.1 y $6.1 \%$, mostrando una humedad menor en los frutos mantenidos a temperatura ambiente y en aquellos almacenados 9 semanas y con la dosis más alta de 1-MCP. Debido a que los frutos de chayote se cosechan en madurez hortícola, no se presentaron cambios significativos en su composición ni por efecto del almacenamiento, con valores de acidez total y de sólidos solubles totales bajos $\left(0.1 \%\right.$ y entre 4 y $5{ }^{\circ} \mathrm{Bx}$, respectivamente) (Cuadro 1$)$. Estos valores son similares a lo reportado en pepino (Cucumis sativus) una hortaliza perteneciente a la familia Cucurbitácea cuyos valores se ubican entre 3 y 4 Bx (Barraza-Álvarez, 2015). 
Se puede observar que los contenidos de clorofila $a$ y $b$ de los frutos nigrum spinosum va de 3.94 a $7.44 \mathrm{mg} 100 \mathrm{~g}^{-1}$, con mayor concentración de clorofila $b$ que clorofila $a$, que explica su color verde, así como su origen de zonas templadas y valles altos. El cultivo de chayote espinoso predomina en altitudes superiores al bosque mesófilo (1 600 a $2800 \mathrm{msnm}$ ) en los Estados de Veracruz, Michoacán, Puebla y México, bajo estas condiciones de altura y entorno, generalmente la concentración de clorofila es mayor a fin de aprovechar mejor la escasa irradiación incidente. Por otro lado, en el caso de los frutos del genotipo virens levis, cultivados en lugares de menor altitud, su color es verde-amarillo y con una concentración significativamente menor de clorofila que nigrum spinosum (Cadena et al., 2007; Azcón-Bieto y Talon, 2003) (Cuadro 1).

Cuadro 1. Contenido de humedad, acidez titulable (\% AT), sólidos solubles totales (\% SST) y clorofila (mg $100 \mathrm{~g}^{-1}$ ) en chayote nigrum spinosum bajo diferentes tiempos de almacenamiento y dosis de 1-MCP.

\begin{tabular}{|c|c|c|c|c|c|c|}
\hline Factor & Nivel & Humedad (\%) & $\operatorname{AT}(\%)$ & $\operatorname{SST}\left({ }^{\circ} \mathrm{Bx}\right)$ & $\mathrm{C}_{\mathrm{a}}\left(\mathrm{mg} 100 \mathrm{~g}^{-1}\right)$ & $\mathrm{C}_{\mathrm{b}}\left(\mathrm{mg} 100 \mathrm{~g}^{-1}\right)$ \\
\hline \multirow[t]{4}{*}{ SEAL } & 0 & $93.89 \mathrm{~b}$ & $0.11 \mathrm{ab}$ & $4.46 \mathrm{~b}$ & $1.47 \mathrm{c}$ & $2.06 \mathrm{c}$ \\
\hline & 3 & $94.52 \mathrm{a}$ & $0.09 \mathrm{c}$ & $4.99 \mathrm{a}$ & $2.47 \mathrm{bc}$ & $3.7 \mathrm{bc}$ \\
\hline & 6 & $94.56 \mathrm{a}$ & $0.12 \mathrm{a}$ & $5.17 \mathrm{a}$ & $4.75 \mathrm{a}$ & $6.97 \mathrm{a}$ \\
\hline & 9 & $94.13 \mathrm{~b}$ & $0.1 \mathrm{bc}$ & $5.14 \mathrm{a}$ & $3.14 \mathrm{~b}$ & $4.58 \mathrm{~b}$ \\
\hline \multirow[t]{3}{*}{ Dosis 1-MCP } & 0 & $94.9 \mathrm{a}$ & $0.09 \mathrm{~b}$ & $5.15 \mathrm{a}$ & $2.27 \mathrm{~b}$ & $3.41 \mathrm{a}$ \\
\hline & 500 & $93.69 \mathrm{c}$ & $0.11 \mathrm{a}$ & $4.76 \mathrm{~b}$ & $3.11 \mathrm{ab}$ & $4.59 \mathrm{a}$ \\
\hline & 1000 & $94.23 \mathrm{~b}$ & $0.11 \mathrm{a}$ & $4.9 \mathrm{~b}$ & $3.49 \mathrm{a}$ & $4.98 \mathrm{a}$ \\
\hline \multirow[t]{2}{*}{ DSA } & 1 & $94.24 \mathrm{a}$ & 0.11 & $4.99 \mathrm{a}$ & $2.78 \mathrm{a}$ & $4.14 \mathrm{a}$ \\
\hline & 11 & $94.31 \mathrm{a}$ & 0.1 & $4.89 \mathrm{a}$ & $3.13 \mathrm{a}$ & $4.52 \mathrm{a}$ \\
\hline \multicolumn{2}{|c|}{ Semana*1-MCP } & $*$ & $*$ & $*$ & * & * \\
\hline \multicolumn{2}{|c|}{ Semana*día } & $*$ & $*$ & $*$ & $*$ & $*$ \\
\hline \multicolumn{2}{|c|}{ 1-MCP*día } & $*$ & * & ns & ns & ns \\
\hline \multicolumn{2}{|c|}{ Semana*1-MCP*día } & $*$ & * & * & ns & ns \\
\hline
\end{tabular}

$\mathrm{SEAL}=$ semanas de almacenamiento; $\mathrm{AT}=$ acidez titulable; $\mathrm{TA}=$ temperatura ambiente a $20 \pm 2{ }^{\circ} \mathrm{C} ; \mathrm{R}=$ refrigeración a $10{ }^{\circ} \mathrm{C} ; \mathrm{DSA}=$ días de muestreo durante simulación en anaquel; $1-\mathrm{MCP}=$ dosis de $1-\mathrm{MCP} ; \mathrm{SST}=$ sólidos solubles totales; $\mathrm{C}_{\mathrm{a}}=$ clorofila $\mathrm{a} ; \mathrm{C}_{\mathrm{b}}=$ clorofila $\mathrm{b} ; \mathrm{C}_{\mathrm{a}+\mathrm{b}}=$ clorofila total; letras iguales para cada factor con sus niveles no son significativamente diferentes; $\mathrm{ns}=$ no significativo; ${ }^{*}=$ significativo a $p \leq 0.05$.

Con relación al contenido de azúcares este varió de 1.23 a $3.45 \%$ y en promedio de $2.03 \%$ siendo el contenido de fructosa un poco mayor que de glucosa 1.07 y $0.89 \%$ respectivamente y $\sin$ presencia de sacarosa, sin que se presentaran diferencias significativas por efecto de tiempo de almacenamiento, ni aplicación de 1-MCP. El contenido de azúcares en frutos de cucurbitáceas es diverso, en caso de frutos de melón (Cucumis melo L.) genotipo cantalupensis el contenido de azúcares totales se reporta entre $10.2 \%$ con sacarosa como azúcar principal (4.35\%) seguido por fructosa $1.95 \%$ y glucosa $2.1 \%$ (Stepansky et al., 1999).

En el caso de la calabacita (Cucurbita maxima var. Zapallito (Carr.) Millan) se reporta un contenido de azúcares totales menor con 4.27\% (Massolo, 2013). Lo anterior, muestra que el chayote tiene un contenido muy bajo de azúcares, comparado con frutos de la misma familia, por lo que es recomendado en dietas de hospitales no solo por su bajo contenido calórico sino por el alto contenido de fibra dietética superior a frutos como ciruela, kiwi, o mango (Cadena-Iñiguez et al., 2007; Morillas-Ruiz y Delgado-Alarcón, 2012). 
Con relación a la pérdida de peso se observó que los frutos mantenidos a temperatura ambiente fueron similares a los frutos tratados con $500 \mathrm{~nL} \mathrm{~L}^{-1}$ e incidencia de viviparismo del 30 y $10 \%$, respectivamente, al día 11 de almacenamiento, mientras que los frutos tratados con $1000 \mathrm{~nL} \mathrm{~L}^{-1}$ tuvieron solo $10 \%$ de viviparismo al mismo día.

Para el almacenamiento refrigerado, después de 3 semanas los frutos testigo presentaron mayores pérdidas de peso, con $60 \%$ de viviparismo, mientras que los frutos tratados con ambas dosis de 1MCP no presentaron este problema durante los $11 \mathrm{~d}$ de almacenamiento, lo que indica que junto con la baja temperatura la aplicación de 1-MCP inhibieron el viviparismo actuando de forma sinérgica (Figura 3).
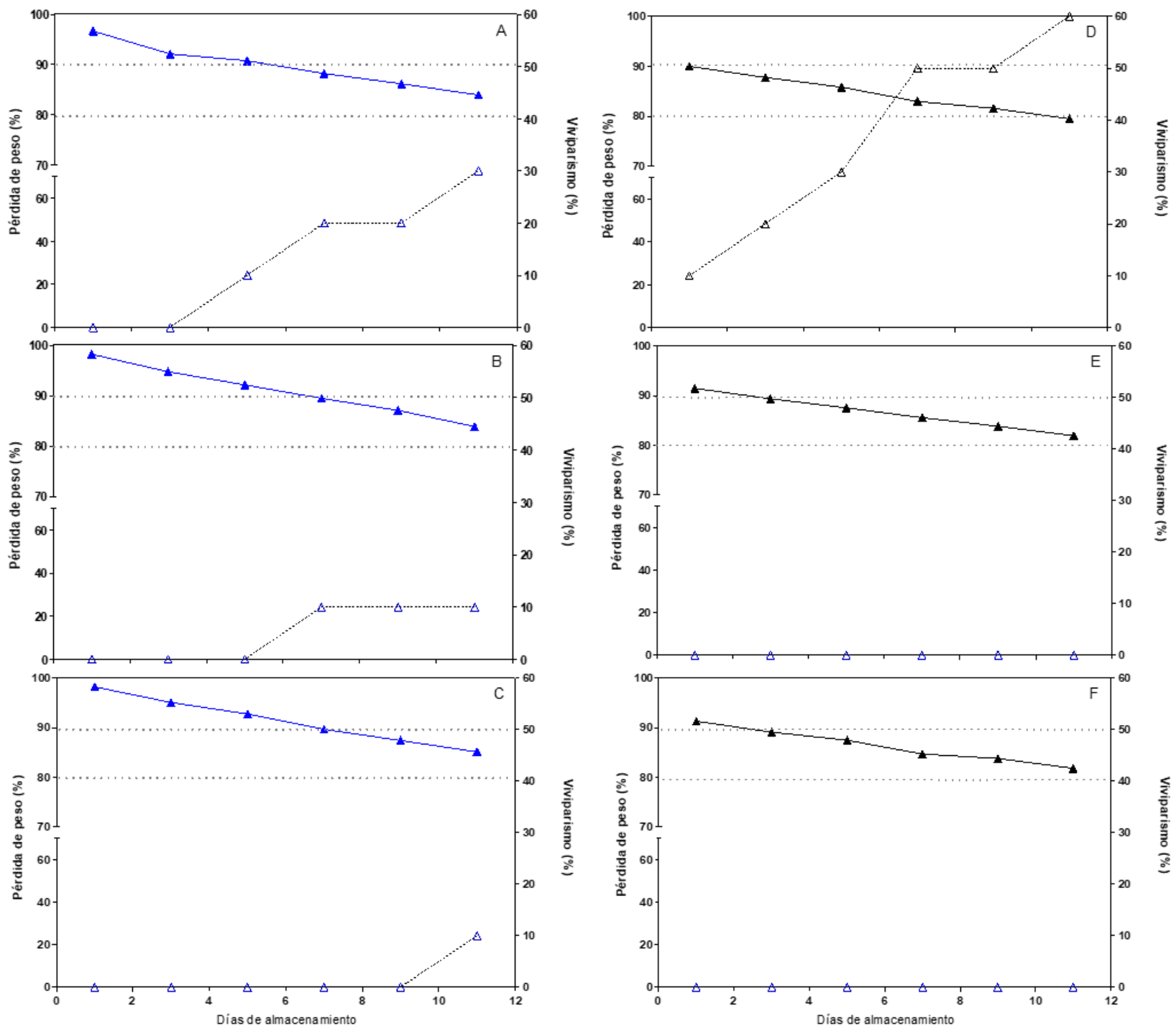

Figura 3. Porcentaje de pérdida de peso y viviparismo de frutos de chayote virens levis. Gráficas A: (0 $\left.\mathrm{nL} \mathrm{L}{ }^{-1}, 1-\mathrm{MCP}\right), \mathrm{B}:\left(500 \mathrm{~nL} \mathrm{~L}{ }^{-1}, 1-\mathrm{MCP}\right)$ y C: $\left(1000 \mathrm{~nL} \mathrm{~L}^{-1}, 1-\mathrm{MCP}\right)$ mantenidos a temperatura ambiente y $\mathrm{D}\left(0 \mathrm{~nL} \mathrm{~L}^{-1}, 1-\mathrm{MCP}\right), \mathrm{E}\left(500 \mathrm{~nL} \mathrm{~L}^{-1}, 1-\mathrm{MCP}\right)$ y $\mathrm{F}\left(1000 \mathrm{~nL} \mathrm{~L}^{-1}, 1-\mathrm{MCP}\right)$ frutos almacenados 3 semanas a $10^{\circ} \mathrm{C}$ y mantenidos a temperatura ambiente por 11 días. 
Aunque el 1-MCP se utiliza mayormente para retrasar el proceso de maduración de frutos climatéricos y en plantas ornamentales con éxito, se ha utilizado de forma limitada en productos no climatéricos, presentando diversas respuestas. Por ejemplo, en fresa, la aplicación de 1-MCP entre 1-1 $000 \mathrm{~nL} \mathrm{~L}^{-1}$ mantuvo el color y la firmeza (Jiang et al., 2001), en pepino se observó poco o ningún efecto benéfico por la aplicación de $1 \mathrm{MCP}$ a menos que exista el riesgo de que haya etileno presente (Nilsson, 2005). En general se observó una correlación positiva entre la pérdida de peso y viviparismo del 0.819 , mientras que no existió una correlación significativa entre las dosis de 1-MCP con viviparismo y pérdida de peso.

Como se muestra en la Figura 4, el tiempo de almacenamiento límite para mantener la calidad de frutos de nigrum spinosum en este trabajo fue de 3 semanas a $10{ }^{\circ} \mathrm{C}$, ya que para las 6 y 9 semanas de almacenamiento las espinas de los frutos estaban deshidratadas y presencia de una alta incidencia severa de hongos, que se acentuó con los frutos tratados con 1-MCP (Figura 4).
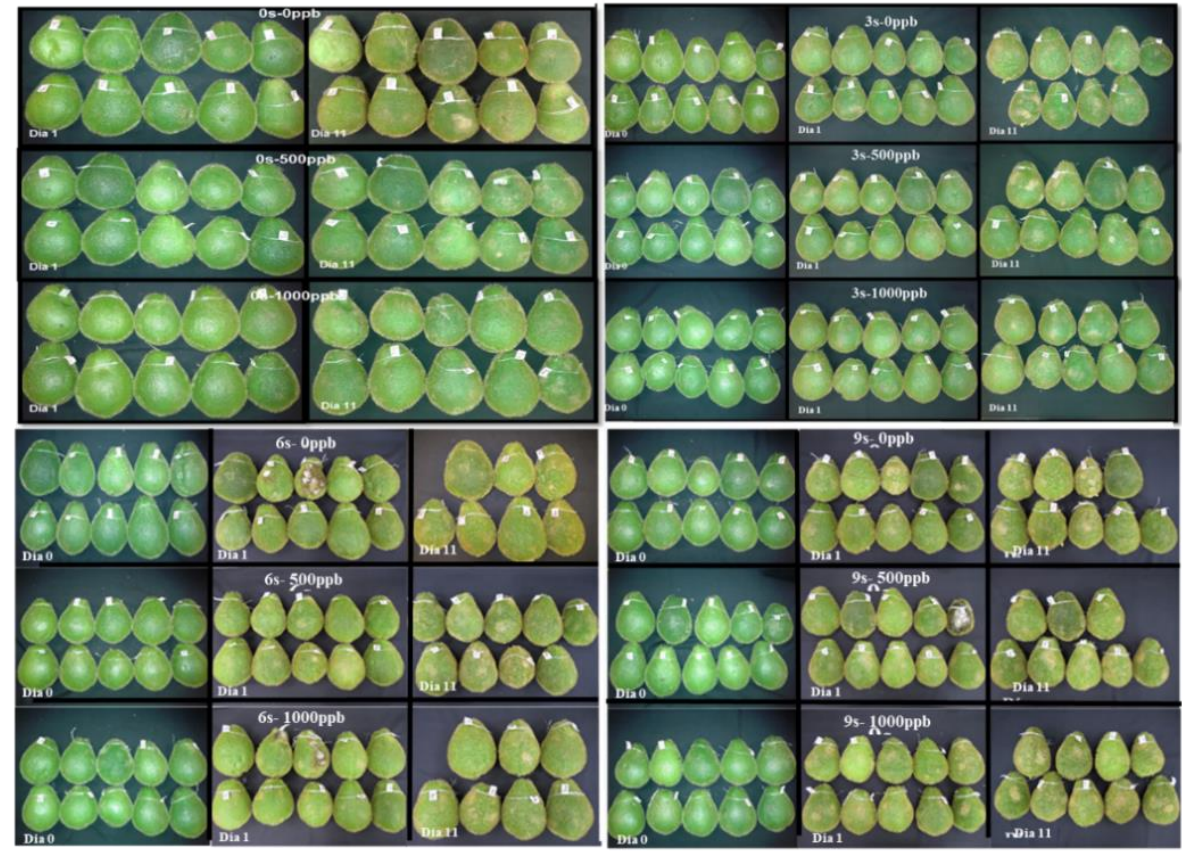

Figura 4. Apariencia de frutos de chayote nigrum spinosum almacenados a diferentes tiempos (temperatura ambiente, $3 \mathrm{~s}$ (tres semanas), 6s (seis semanas) y 9s (nueve semanas) con la aplicación de 1-MCP $\left(0,500\right.$ y $\left.1000 \mathrm{~nL} \mathrm{~L}{ }^{-1}\right)$. Inicial (día 0), salida del almacenamiento (día 1) y 11 días después del almacenamiento (día 11).

\section{Conclusiones}

Los frutos de chayote nigrum spinosum no presentaron cambio significativos es su composición al almacenarlos a temperatura ambiente $\left(20 \pm 2{ }^{\circ} \mathrm{C}\right)$ y a baja temperatura $\left(10 \pm 1^{\circ} \mathrm{C}, 85 \% \mathrm{HR}\right)$, además contienen menor humedad (5.1 a $6.1 \%)$ que el genotipo virens levis, también conservaron sus características de apariencia con el almacenamiento por 3 semanas, pero no a 6 y 9 semanas ya que el fruto y la espina presentaron deshidratación y un color verde opaco, las dosis de 1-MCP (500 y $1000 \mathrm{~nL} \mathrm{~L}^{-1}$ ) redujeron significativamente el viviparismo pero incrementaron la susceptibilidad a la incidencia de hongos, desarrollando pudrición en el fruto. 


\section{Literatura citada}

AOAC. 1990. Official Methods of Analysis. 15 ${ }^{\text {th }}$ (Ed.). Vol. II. Association of Official Analytical Chemist. Washington, D.C. 918-919 pp.

Azcón-Bieto, J. y Talón, M. 2003. Fundamentos de fisiología vegetal. McGraw-Hill. Interamericana. $3^{\mathrm{a}}$ Reimpresión. ISBN: 84-486-0258-7. 207-216 pp.

Barraza-Álvarez, F. V. 2015. Calidad morfológica y fisiológica de pepinos cultivados en diferentes concentraciones nutrimentales. Rev. Colomb. Cienc. Hortíc. 9(1):60-71. Doi.org/10.17584/rcch.2015v9i1.3746.

Blankenship, S. 2001. Ethylene effects and benefits of 1-MCP. Perishables handling quarterly. University of California.108:2-4.

Cadena-Iñiguez, J.; Arévalo-Galarza, L.; Ruiz-Posadas, L. M.; Aguirre-Medina, J. F.; SotoHernández, M.; Luna-Cavazos, M. y Zavaleta-Mancera, H. A. 2006. Quality evaluation and influence of 1-MCP on Sechium edule (Jacq.) Sw. fruit during postharvest. Postharvest Biol. Technol. 40(2):170-176. Doi: 10.1016/j.postharvbio.2005.12.013.

Cadena-Iñiguez, J.; Arévalo-Galarza, L.; Avendaño-Arrazate, C. H.; Soto-Hernández, M.; RuizPosadas, L. M.; Santiago-Osorio, E.; Acosta-Ramos, M.; Cisneros-Solano, V. M.; AguirreMedina, J. F. and Ochoa-Martínez, D. 2007. Production, genetics, postharvest management and pharmacological characteristics of Sechium edule (Jacq.) Sw. Fresh Produce, Global Science Books. 1(1):41-52.

Cadena-Iñiguez, J.; Hernández-Soto, M.; Arévalo- Galarza, M.L.; Avendaño-Arrazate, C. H.; Aguirre Medina, J. F. y Ruiz-Posadas, L. M. 2011. Caracterización bioquímica de variedades domesticadas de chayote. Chapingo Serie Horticultura. 17(2):45-55.

Di-Rienzo, J. A.; Casanoves, F.; Balzarini, M. G.; González, L.; Tablada, M. y Robledo, C. W. InfoStat versión 2016. Grupo InfoStat, FCA. Universidad Nacional de Córdoba, Argentina. http://www.infostat.com.ar. 91-119 pp.

Jensen, L. P. and Lai, A. R. 1986. Chayote (Sechium edule) causing hypokalemia in pregnancy. Am. J. Obstetrics and Gynecol. 5:1048-1049.

Jiang, Y.; Joyce, D. C. and Terry, L. A. 2001. 1-Methylcyclcopropene treatment affects strawberry fruit decay. Postharvest Biol. Technol. 23(3):227-232. Doi:10.1016/S09255214(01)00123-5.

Lichtenthaler, H. K. 1987. Chlorophylls and carotenoids: pigments of photosynthetic membranes. Methods in Enzymol. 623(148): 350-382. dx.doi.org/10.1016/0076-6879(87)48036-1.

Massolo, J. F.; Concellón, A.; Chaves, A. R. and Vicente, A. R. 2013. Use of 1-methylcyclopropene to complement refrigeration and ameliorate chilling injury symptoms in summer squash. CyTA-Journal of Food. 11(1):19-26. Doi: 10.1080/19476337.2012.676069.

Minitab Inc. 2018. Minitab ${ }^{\circledR}$ Statistical Software. 2018. http//: www.minitab.com.

Morillas-Ruiz, J. M. y Delgado-Alarcón, J. M. 2012. Análisis nutricional de alimentos vegetales con diferentes orígenes: evaluación de capacidad antioxidante y compuestos fenólicos totales. Nutr. Clín. Diet. Hosp. 32(2):8-20.

Nilsson, T. 2005. Effects of ethylene and 1-MCP on ripening and senescence of European seedless cucumbers. Postharvest Biol. Technol. 36(2):113.125. Doi: 10.1016/j.postharvbio. 2004.11.008.

SINAREFI. 2015. http://www.sinarefi.org.mx/redes/red_chayote.htmL\#cajaIntro. 
Sisler, E. C. and Serek, M. 1997. Inhibitors of ethylene responses in plants at the receptor level: recent developments. Physiol. Plant. 100(3):577-582. Doi.org/10.1111/j.1399-3054. 1997.tb03063.x.

Stepansky, A.; Kovalski, I.; Schaffer, A. A. and Perl-Treves, R. 1999. Variation in sugar levels and invertase activity in mature fruit representing a broad spectrum of Cucumis melo genotypes. Gen. Res. Crop Evol. 46(1):53-62. Doi.org/10.1023/A:1008636732481. 